\title{
Carthamin yellow inhibits matrix degradation and inflammation induced by LPS in the intervertebral disc via suppression of MAPK pathway activation
}

\author{
BIN CHEN, HAN-TAO WANG, BO YU, JI-DONG ZHANG and YU FENG \\ Department of Orthopaedic Surgery, Renji Hospital, School of Medicine, \\ Shanghai Jiao Tong University, Shanghai 200127, P.R. China
}

Received November 15, 2016; Accepted June 2, 2017

DOI: $10.3892 /$ etm.2017.4645

\begin{abstract}
Carthamin yellow (CY), which is a flavonoid compound isolated fromsafflower, has variouspharmacological effects including promoting blood circulation to remove blood stasis and alleviating pain. CY is a herb used in Chinese traditional medicines. Intervertebral disc degeneration (IDD) is a common spinal disorder and degeneration of nucleus pulposus (NP) cells and inflammation are significant parts of the pathological cascade. The curative effect of CY on NP cells in association with degeneration and inflammation remains to be elucidated. In the present study, rat NP cells were isolated, cultured and used to detect the suppressive effects of CY on lipopolysaccharide (LPS)-induced genetic expression variation and the expression of matrix degradation enzymes, including matrix metallopeptidase-3, ADAM metallopeptidase with thrombospondin type 1 motif (ADAMTS)-4 and ADAMTS-5. A protective effect of CY on NP cells was observed against LPS-induced matrix degradation and inflammation. Western blotting results demonstrated that pretreatment with CY significantly suppressed the LPS-induced activation of the mitogen activated protein kinase (MAPK) pathway. The results of the present study suggested that $\mathrm{CY}$ exerted anti-degenerative and anti-inflammatory effects on NP cells via inhibition of MAPK pathway activation. Therefore, CY may be a potential therapeutic drug for the treatment of IDD in the future.
\end{abstract}

\footnotetext{
Correspondence to: Dr Yu Feng or Dr Ji-Dong Zhang, Department of Orthopaedic Surgery, Renji Hospital, School of Medicine, Shanghai Jiao Tong University, 160 Pujian Road, Shanghai 200127, P.R. China

E-mail: docyufeng@163.com

E-mail: medjdzhang@126.com
}

Key words: carthamins yellow, intervertebral disc, nucleus pulposus cells, degeneration, inflammation

\section{Introduction}

Intervertebral disc degeneration (IDD) is a common spinal disorder and is characterized by clinical signs ranging from low back pain (LBP) to neurological deficits. In addition, LBP is one of the most common musculoskeletal complaints in the world, and it has become a severe socioeconomic and health issue influencing of our society. Previous studies have exhibited that the mechanism of IDD includes a complicated biochemical process. One of the most important characteristics of IDD is the deficiency of proteoglycan (PG) content in intervertebral discs (IVDs). This process is closely related to the gene expression of ADAMTSs (activity of disintegrins and metalloproteinases with thrombospondin motifs), MMPs (matrix metalloproteinases) and TIMPs (tissue inhibitors of metalloproteinases) (1-7). As a strong inflammatory stimulation factor, previous researches have revealed that lipopolysaccharide (LPS) can lead to gene upregulation and the secretion of diverse proinflammatory cytokines and matrix-degrading enzymes, including ADAMTSs and MMPs in NP cells, thereout causing a decrease in PG volume and IDD $(8,9)$. Moreover, proinflammatory cytokines such as tissue necrosis factor- $\alpha$ (TNF- $\alpha$ ) also play important parts in IDD $(10,11)$. Cell factors do not affect the IVD like ADAMTSs or MMPs do directly; instead of that, they expedite IDD by inducing the production of inflammatory factors by the intervertebral disc cells. As a TLR ligand, LPS can initiate TLR signaling in intervertebral disc cells, resulting in the up-regulated expression of proinflammatory cytokines and MMPs. Apart from MMPs and ADAMTSs, cytokines can also promote the chemokine ligand (CCL) expression in intervertebral disc cells. In terms of previous studies, CCLs can induce macrophage migration into the IVD, deteriorating the inflammatory stage and causing pain (12-17).

Traditional Chinese medicines (TCMs) are experience-based remedies derived from hundreds or thousands of years of clinical use in China. Most TCMs are extracted from one or more medicinal herbs. The existence of multiple bioactive ingredients makes many TCMs potential novel resources for the discovery of new anti-inflammatory and anti-matrix degradation drugs $(18,19)$. Thus far, many naturally occurring phytochemicals were reported to possess anti-inflammatory 
and anti-matrix degradation effect and got considerable research attention.

Carthamins yellow (CY), which is the flavonoid compounds derived from safflower, has been extensively used as a natural food color additive in China. Safflower is known as the herb used in traditional medicines that promotes blood circulation to remove blood stasis and alleviate pain $(20,21)$. Safflower injection has been used clinically for cerebrovascular disease, coronary heart disease, and angiitis in China $(22,23)$. However, the effects and potential mechanisms of $\mathrm{CY}$ in inflammation and matrix degradation in the intervertebral disc desease has not yet been illuminated. Therefore, the purpose of our study was to evaluate the anti-inflammatory and anti-matrix degradation effect of CY in the IDD and investigate its potential mechanisms.

\section{Materials and methods}

Main reagents. CY and LPS was purchased from Sigma-Aldrich (St. Louis, MO, USA). CY was dissolved in DMSO at concentrations of $1 \mathrm{~mol} / \mathrm{l}$. And it was stored at $-20^{\circ} \mathrm{C}$. The additional proportion of DMSO in the culture medium was less than $0.05 \%$. LPS was dissolved in PBS at concentrations of $1 \mathrm{mg} / \mathrm{ml}$ and was stored at $4^{\circ} \mathrm{C}$. The P-ERK, ERK, P-JNK, JNK, P-P38, P38 and GAPDH antibody and secondary antibody were purchased from Cell Signaling Technology, Inc. (Beverly, MA, USA). Collagen II and aggrecan were purchased from Abcam (Cambridge, UK). The IHC secondary antibody was MaxVision TM HRP-Polymer kit from Maixin Bio (Fuzhou, China).

NP cell isolation and culture. The present study was conducted in strict accordance with the recommendations in the Guide for the Care and Use of Laboratory Animals of the National Institutes of Health. NP cells were isolated from the lumbar spines of Sprague Dawley rats (6-8 weeks old, mixed male and female), using standard enzymatic digestion and culture in complete media (high-glucose DMEM with $10 \% \mathrm{FBS}$, $100 \mathrm{U} / \mathrm{ml}$ penicillin and $100 \mathrm{mg} / \mathrm{ml}$ streptomycin) up to passage $2-3$ at $37^{\circ} \mathrm{C}$ in a humidifed atmosphere with $5 \% \mathrm{CO}_{2}$.

Cell cytotoxicity assay. A cell counting kit-8 (CCK8) (Dojindo, Kumamoto, Japan) was used to test the viability of NP cells after CY treatment for 1 day according to previously reported methods (24). Approximately $5 \times 10^{3}$ NP cells were seeded on each film and transferred to 96 -well plates. incubated with various concentrations of $\mathrm{CY}$ for $24 \mathrm{~h}$. The conditioned culture medium was removed before CCK8 examination. Subsequently, $100 \mu 1$ of DMEM and $10 \mu \mathrm{l}$ of CCK8 solution were added to each well, followed by CCK 8 incubation at $37^{\circ} \mathrm{C}$ for $2.5 \mathrm{~h}$. The optical density (OD) at $450 \mathrm{~nm}$ was determined using a microplate reader (BioTek, Winooski, VT, USA). Cell viability was calculated as follows: Cell viability to control $(\%)=\left(\mathrm{OD}_{\text {drug-treated group }}-\mathrm{OD}_{\text {blank }}\right) /\left(\mathrm{OD}_{\text {control group }}-\mathrm{OD}_{\text {blank }}\right)$.

Apoptosis assay. Cell apoptosis was measured by flow cytometry using Annexin V/propidium iodide (PI) double-immunofluorescent staining according to previously reported methods (25). NP cells were cultured with $200 \mu \mathrm{M}$ $\mathrm{CY}$ and/or $1 \mu \mathrm{g} / \mathrm{ml}$ LPS for $24 \mathrm{~h}$. Then the cells were washed with cold PBS and resuspended with $1 \mathrm{X}$ Annexin-binding buffer. After that, all cells were stained with Annexin V-FITC and Propidium iodide according to the manufacturer's protocols. The apoptosis rate was measured by flow cytometry (FCM). Apoptotic events were indicated as a combination of fluorescein isothiocyanate (FITC)+/PI- (early apoptotic) and FITC+/PI+ (late apoptotic or dead) events. The final results are expressed as the percentage of early, late and total apoptotis.

Gene expression. NP cells were incubated with different concentrations of CY and $1 \mu \mathrm{g} / \mathrm{ml}$ LPS for $24 \mathrm{~h}$. LPS could induce inflammation and matrix degradation in IVD. Total RNA was isolated by the AxyPrep ${ }^{\text {TM }}$ Multisource Total RNA Miniprep kit (Axygen Biosciences, Union City, CA, USA). Then $1 \mu \mathrm{g}$ RNA was converted into complementary DNA (cDNA) with PrimeScript ${ }^{\mathrm{TM}}$ RT reagent kit (Takara Bio, Inc., Otsu, Japan). Quantitative PCR was performed using an ABI 7500 Sequencing Detection System and SYBR ${ }^{\circledR}$ Premix Ex Taq ${ }^{\mathrm{TM}}$ (Takara Bio, Inc.). Cycling conditions were as follows: 40 cycles at $95^{\circ} \mathrm{C}$ for $5 \mathrm{sec}$ and $60^{\circ} \mathrm{C}$ for $34 \mathrm{sec}$. The primers were used to amplify target genes are listed in Table I. The primers were designed and selected using blast in pubmed, and GAPDH was used as the internal control.

Western blotting. For signaling pathway protein assay, the cells were treated with various concentrations of CY and/or $1 \mu \mathrm{g} / \mathrm{ml}$ LPS for $24 \mathrm{~h}$. For aggrecan and collagen II protein assay, the cells were treated with various concentrations of $\mathrm{CY}$ and/or $1 \mu \mathrm{g} / \mathrm{ml}$ LPS for 5 or 8 days. Cell total proteins were extracted using NE-PER ${ }^{\circledR}$ Nuclear and Cytoplasmic Extraction Reagents according to the manufacturer's instructions. $20 \mu \mathrm{g}$ protein (each sample) was loaded into gel, and separated by $7.5-12.5 \%$ SDS-PAGE, then transferred to $0.22-\mu \mathrm{m}$ PVDF membranes (Millipore Corp., Billerica, MA, USA). The membranes were blocked with $5 \%$ fat-free milk at room temperature for $1 \mathrm{~h}$ and subsequently incubated with primary antibodies overnight at $4^{\circ} \mathrm{C}$ (1:1,000 dilution, Cell Signaling Technology). After three washes in TBST, the membranes were probed with the corresponding secondary antibody for $1 \mathrm{~h}$ at room temperature. The membranes were washed again in TBST, and the protein bands were visualized using an Odyssey Infrared Imaging System (LI-COR Biosciences, Lincoln, NE, USA). Positive immunoreactive bands were densitometrically quantified and normalized to GAPDH.

Immunohistochemistry staining. $2 \times 10^{4} / \mathrm{ml}$ cells were seeded in 24-well plates, and these NP cells were cultured with diverse CY concentrations and/or $1 \mu \mathrm{g} / \mathrm{ml}$ LPS for 5 or 8 days. Cells were fixed with $4 \%$ paraformaldehyde before making cells slides. After fixation, NP cells were treated with $0.1 \%$ Triton X-100 for $15 \mathrm{~min}$. Then the cells were blocked with $2 \%$ bovine serum albumin (Sigma-Aldrich) for $1 \mathrm{~h}$. Then, cells slides were incubated with the corresponding antibody, including anti-collagen II and anti-aggrecan antibody (1:200 dilution; Abcam) overnight at $4{ }^{\circ} \mathrm{C}$. For immunohistochemistry, the secondary antibody was used for $15 \mathrm{~min}$ at room temprature. The DAB (Maixin Bio) solution was used as the chromogen. We used an inverted microscope microscopy (Olympus, Tokyo, Japan) to acquire the images. The integral 
Table I. Sequences of primers used in quantitative PCR.

\begin{tabular}{ll}
\hline Gene & \multicolumn{1}{c}{ Primer sequences (5'-3') } \\
\hline TNF- $\alpha$ & $\begin{array}{l}\text { Forward: GGCTTTCGGAACTCACTGGA } \\
\text { Reverse: GGGAACAGTCTGGGAAGCTC }\end{array}$ \\
Collagen II & $\begin{array}{l}\text { Forward: GGCCAGGATGCCCGAAAATTA } \\
\text { Reverse: ACCCCTCTCTCCCTTGTCAC }\end{array}$ \\
Aggrecan & Forward: CAGATGGCACCCTCCGATAC \\
& Reverse: GACACACCTCGGAAGCAGAA \\
ADAMT-4 & Reverse: ACCGATTACCAGCCTTTGGG \\
& Forward: CCGACTCCGGATCTCCATTG \\
ADAMT-5 & Forward: CCGAACGAGTTTACGGGGAT \\
& Reverse: TGTGCGTCGCCTAGAACTAC \\
MMP3 & Forward: TTTGGCCGTCTCTTCCATCC \\
& Reverse: GCATCGATCTTCTGGACGGT \\
GAPDH & Forward: TGCCACTCAGAAGACTGTGG \\
& Reverse: TTCAGCTCTGGGATGACCTT
\end{tabular}

optical density (IOD) of every photo was measured using the Image-Pro Plus 6.0 software (Media Cybernetics, Inc., Rockville, MD, USA).

Statistical analysis. The statistical package for the social sciences (SPSS) version 19.0 was used to analyze the data. The significance of differences between experimental groups and controls were assessed using the Student's t-test or one-way analysis of variance (ANOVA) as appropriate. The data are expressed as the mean $\pm \mathrm{SD}$. $\mathrm{P}<0.05$ was considered to indicate a statistically significant difference.

\section{Results}

Cell viability of NP cells after CY treatment. To study the potential cytotoxicity of $C Y$, we measured the cell viability of NP cells. After incubating with different concentrations of CY for $24 \mathrm{~h}$, we used CCK-8 to assay the cell viability of NP cells. As shown in Fig. 1, CY did not inhibit proliferation of NP cells at concentration of 50, 100 and $200 \mu \mathrm{M}$.

Apoptosis analysis of NP cells following CY treatment. To verify the cytotoxicity of $\mathrm{CY}$, we examined the apoptosis rate of NP cells after treating with CY for $24 \mathrm{~h}$. CY could decrease the early apoptosis rate at $200 \mu \mathrm{M}$ with $1 \mu \mathrm{g} / \mathrm{ml} \mathrm{LPS}(2.47 \%$ in $1 \mu \mathrm{g} / \mathrm{ml}$ LPS vs. $1.93 \%$ which were treated with CY of $200 \mu \mathrm{M}$ and $1 \mu \mathrm{g} / \mathrm{ml} \mathrm{LPS}, \mathrm{P}<0.05)$, and $\mathrm{CY}$ could increase the late apoptosis rate at $200 \mu \mathrm{M}$ with $1 \mu \mathrm{g} / \mathrm{ml} \operatorname{LPS}(0.58 \%$ in $1 \mu \mathrm{g} / \mathrm{ml}$ LPS vs. $1.36 \%$ which were treated with CY of $200 \mu \mathrm{M}$ and $1 \mu \mathrm{g} / \mathrm{ml} \mathrm{LPS}, \mathrm{P}<0.05)$, but the total apoptosis has no difference between two groups (Fig. 2A). And quantitative data of early, late and total apoptosis rate was consistant with this phenomenon (Fig. 2B-D).

CY inhibited LPS induced matrix-degradation in NP cells. NP cells were incubated with $1 \mu \mathrm{g} / \mathrm{ml}$ LPS in the various concentration of CY (100 or $200 \mu \mathrm{M})$ for 5 or 8 days. After that, we detected extracellular matrix content by cell immunohistochemistry. Our results indicated that the expression

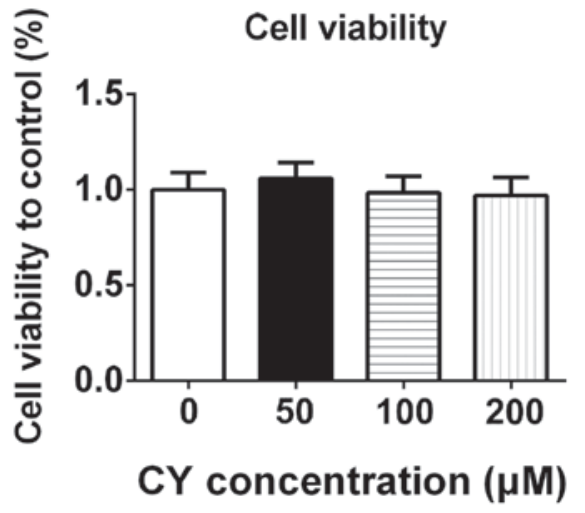

Figure 1. Cell viability assay of NP cells. $5 \times 10^{3} / \mathrm{ml}$ cells were seeded onto 96-well plates, and these cells were cultured with various concentrations of CY for $24 \mathrm{~h}$ after adherence. Then, we used CCK-8 to measure the cell viability of NP cells. CY had no effect in NP cells following $24 \mathrm{~h}$ treatment. Data are presented as the means \pm SD. All data were obtained from at least three independent experiments.

of collagen II and aggrecan increased over time in NP cells, while LPS strikingly decreased the aggrecan and collagen II amount (Fig. 3A). Immunohistochemistry staining showed CY significantly increased the content of aggrecan and collagen II compared to the LPS groups (Fig. 3A). The quantification of IOD also indicated that the CY group gained more aggrecan and collagen II staining (Fig. 3B and C).

After incubated with LPS and various concentration of CY for 5 or 8 days, we also used western blotting to measure the collagen II and aggrecan protein content. The result was similar with immunohistochemistry staining. As shown in Fig. 4, LPS induced collagen II and aggrecan protein down-expression, and CY significantly attenuated the collagen II and aggrecan loss at day 5 and 8 . This effect was more obvious at day 8 (Fig. 4).

$C Y$ reversed $L P S$ induced gene expression changes in NP cells. NP cells were stimulated with $1 \mu \mathrm{g} / \mathrm{ml}$ LPS and 0,100 or $200 \mu \mathrm{M}$ CY, followed by quantitative PCR assay. PCR results showed that LPS significantly up-regulated the gene expression of proinflammatory cytokines TNF- $\alpha$ (Fig. 5A). LPS also down-regulated the gene expression of collagen II and aggrecan in NP cells, which was reversed by CY (Fig. 5B and C). And CY also inhibited multiple matrix-degrading enzymes (MMP-3, ADAMTS-4 and ADAMTS-5) gene overexpression induced by LPS in NP cells (Fig. 5D-F).

CY inhibited the LPS-induced activation of the MAPK pathway in NP cells. We measured the activation of the MAPKs pathway related proteins by western blotting to evaluate the potential mechanisms of effects of CY on LPS induced NP cells. Cells were pretreated with various concentrations of $\mathrm{CY}$ for $2 \mathrm{~h}$, then treated with or without $1 \mu \mathrm{g} / \mathrm{ml}$ LPS for $30 \mathrm{~min}$. The results showed that $1 \mu \mathrm{g} / \mathrm{ml}$ LPS significantly activated the MAPKs pathways by promoting JNK, ERK and P38 protein phosphorylation (Fig. 6). And CY could inhibit the phosphorylation of JNK, ERK and P38 in a dose dependent manner (Fig. 6). This result indicated the MAPKs pathway was involved while CY exerted anti-inflammatory effect in NP cells. 


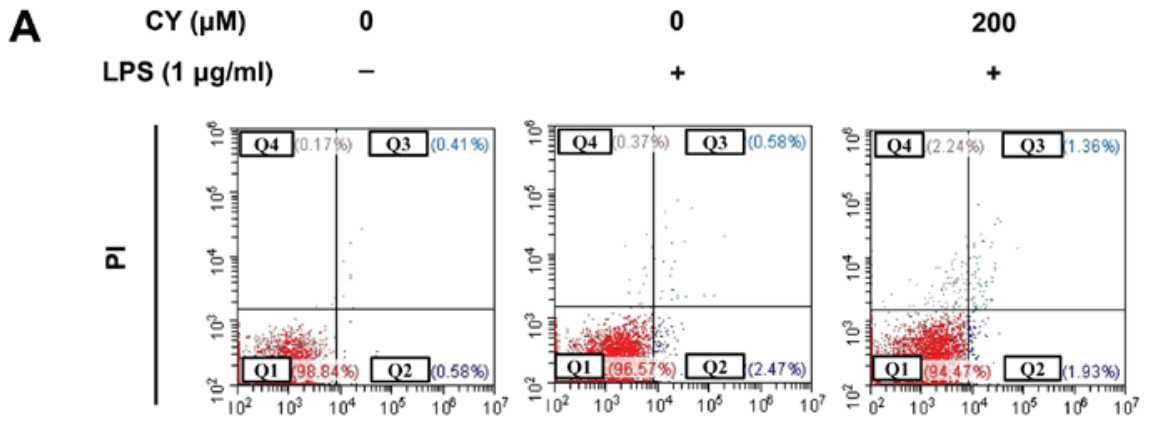

Annexin V-FITC

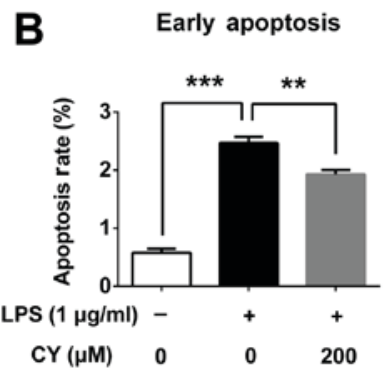

C Late apoptosis

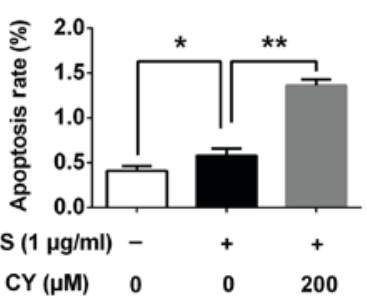

D Total apoptosis

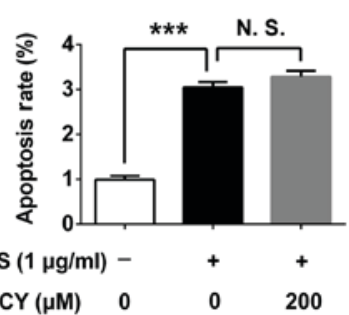

Figure 2. Apoptosis assay of NP cells following CY treatment. (A) After stimulation with or without $1 \mu \mathrm{g} / \mathrm{ml}$ LPS and $200 \mu \mathrm{M} \mathrm{CY}$ for $24 \mathrm{~h}$, cells were stained with Annexin V-FITC and Propidium iodide and the apoptosis rate was measured via flow cytometry. (B-D) The early, late and total apoptosis rate was calculated and compared. The data are presented as the means $\pm \mathrm{SD} .{ }^{* * * *} \mathrm{P}<0.001 ;{ }^{* *} \mathrm{P}<0.01 ;{ }^{*} \mathrm{P}<0.05$. All data were obtained from at least three independent experiments.

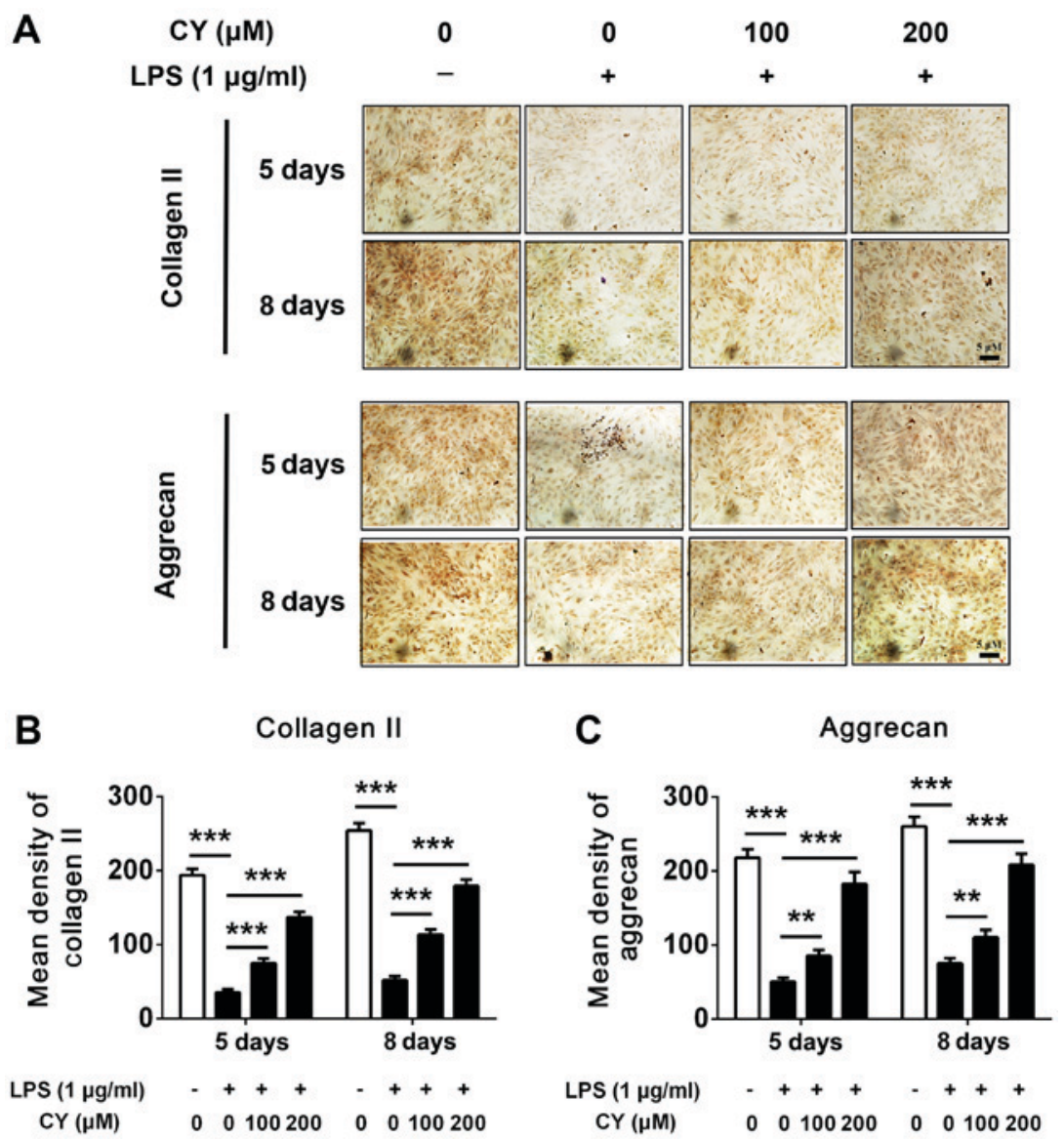

Figure 3. Immunohistochemistry staining of NP cells after CY treatment. (A) $2 \times 10^{4} / \mathrm{ml}$ cells were seeded in a 24 -well plates, and these cells were cultured with different concentrations of CY and/or $1 \mu \mathrm{g} / \mathrm{ml}$ LPS for 5 or 8 days, then cells were fixed with $4 \%$ paraformaldehyde and performed immunohistochemistry staining of collagen II and aggrecan. (B and C) The immunohistochemistry staining of collagen II and aggrecan were quantified by integrated optical density (IOD). The data are presented as the means $\pm \mathrm{SD} .{ }^{* * *} \mathrm{P}<0.001,{ }^{* *} \mathrm{P}<0.01$. All data were obtained from at least three independent experiments. 


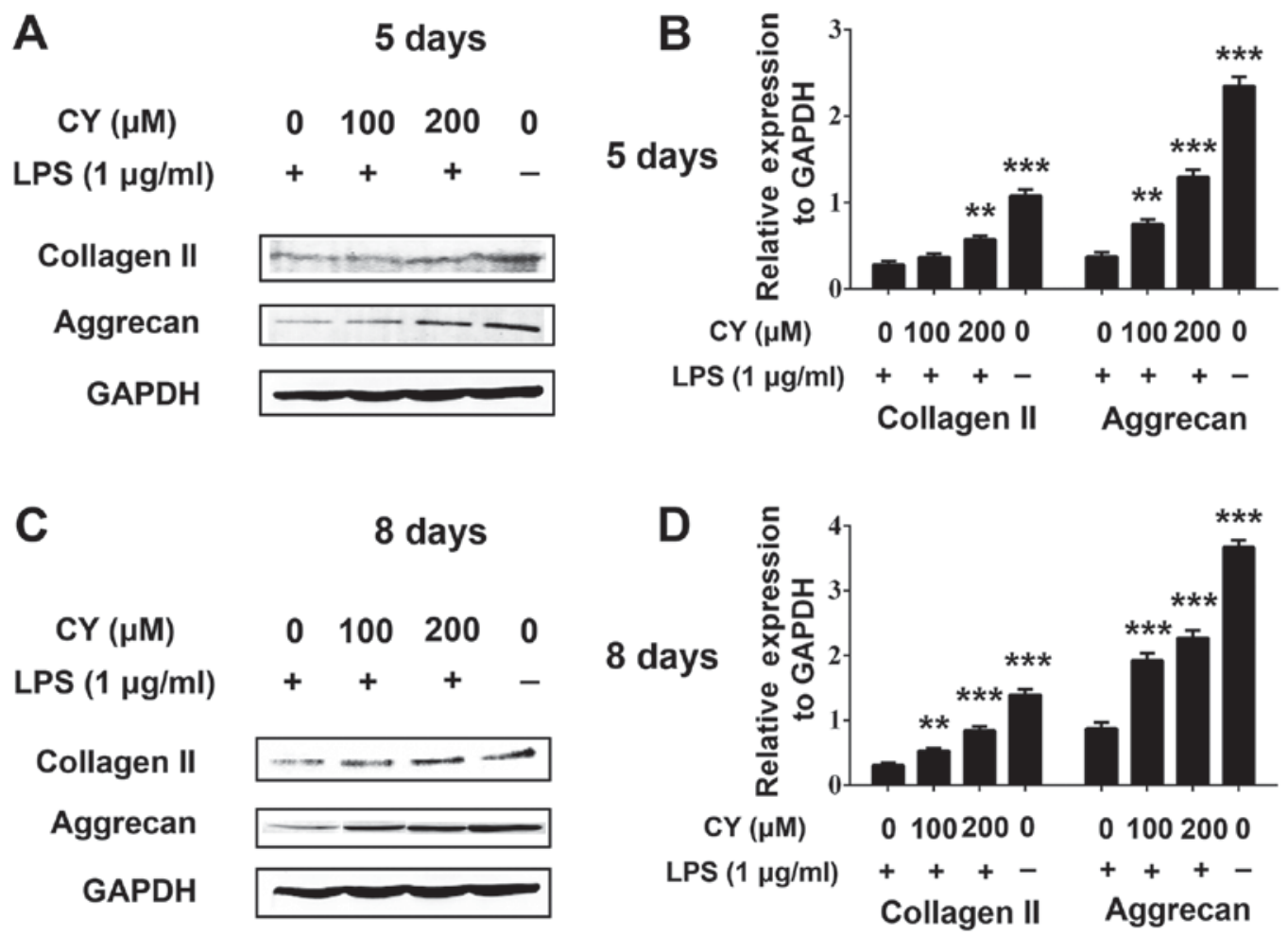

Figure 4. Matrix related protein expression of NP cells after CY treatment. Western blotting used to measure aggrecan and collagen II protein expression of NP cells. Cells were cultured with different concentrations of CY and/or $1 \mu \mathrm{g} / \mathrm{ml}$ LPS for 5 or 8 days, then total protein of cells were extracted and performed western blotting. (A and C) Expression of collagen II and aggrecan at 5 and 8 days. (B and D) Positive immunoreactive bands were densitometrically quantified and normalized to GAPDH. The data are presented as the means $\pm \mathrm{SD} .{ }^{* * * *} \mathrm{P}<0.001,{ }^{* *} \mathrm{P}<0.01$. All data were obtained from at least three independent experiments.
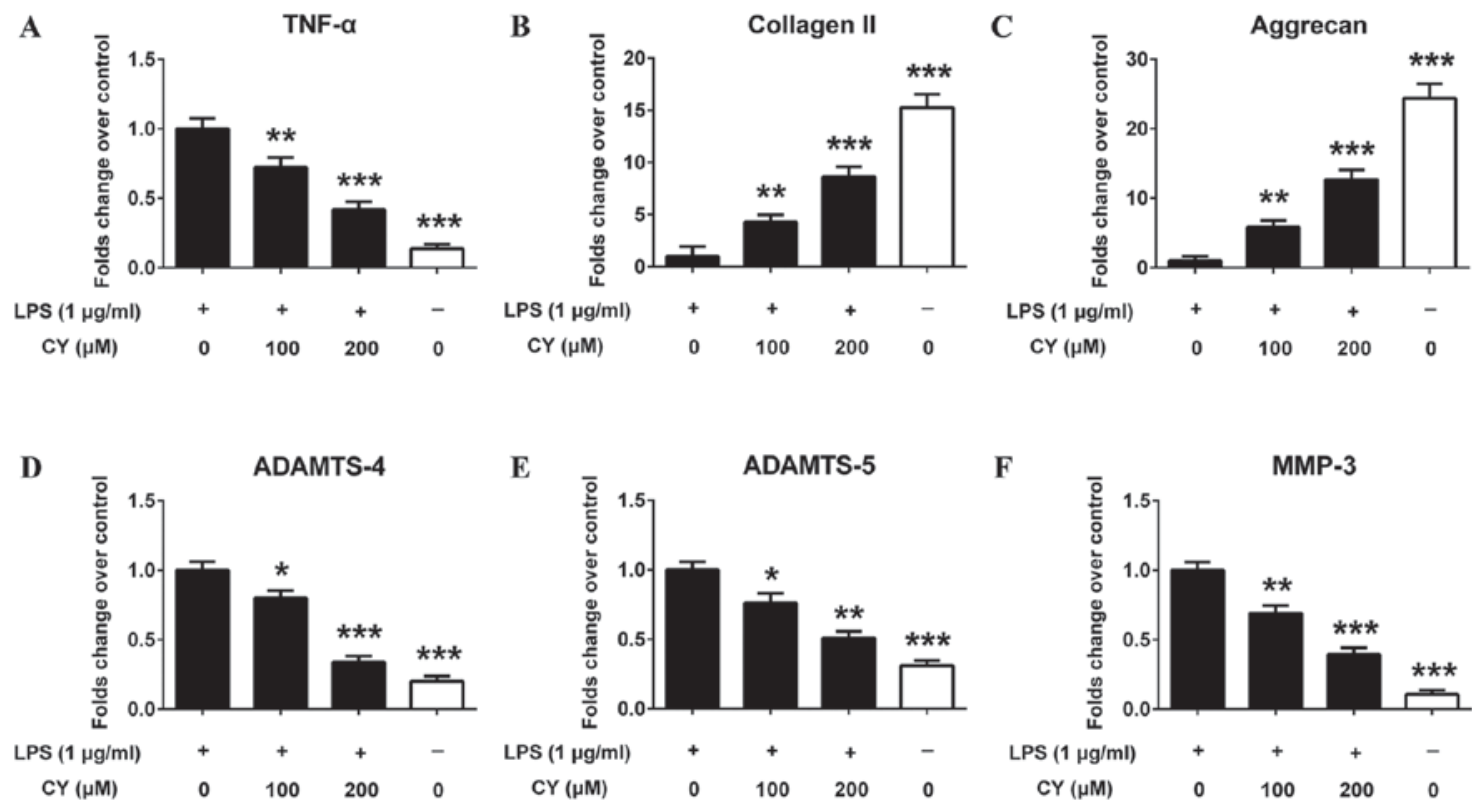

Figure 5. Gene expression changes in NP cells following CY treatment. (A-F) NP cells were treated with or without $1 \mu \mathrm{g} / \mathrm{ml}$ LPS and various concentrations of $\mathrm{CY}$ for $24 \mathrm{~h}$. Then the gene expression of TNF- $\alpha$, collagen II, aggrecan, ADAMTS-4, ADAMTS-5 and MMP-3 were measured by quantitative PCR. GAPDH was used as the internal control. The data are presented as the means $\pm \mathrm{SD}$. ${ }^{* * *} \mathrm{P}<0.001,{ }^{* *} \mathrm{P}<0.01,{ }^{*} \mathrm{P}<0.05$. All data were obtained from at least three independent experiments.

\section{Discussion}

At present, CY has already been widely used as a bioactive natural products and food additive in China (26). However, there is no study focus on the potential therapeutic effect of CY in intervertebral disc degeneration. In our study, we tested the cytotoxicity of CY to NP cells by CCK8 and apoptosis assay firstly. The results showed that CY did not inhibit 
$\mathrm{A} \quad \mathrm{CY}(\mu \mathrm{M}) \quad 01002000$
$\operatorname{LPS}(1 \mu \mathrm{g} / \mathrm{ml})++++$

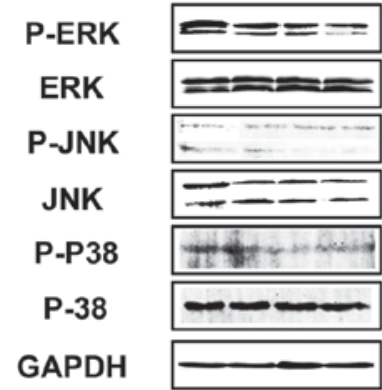

B

P-ERK/ERK

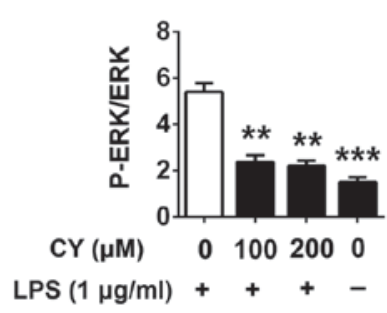

P-JNKIJNK

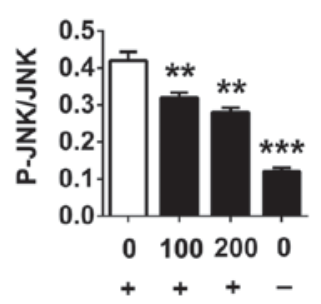

P-P38/P38

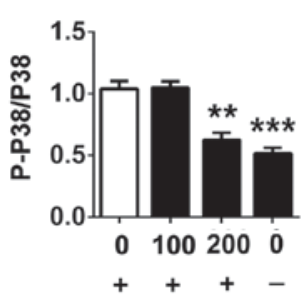

Figure 6. Effect of CY on LPS induced activation of MAPK pathway in NP cells. (A) NP cells were pretreated with various concentrations of CY for 2 h, then treated with or without $1 \mu \mathrm{g} / \mathrm{ml}$ LPS for $30 \mathrm{~min}$. The expression of MAPKs pathway proteins was measured by western blotting. (B) Positive immunoreactive bands were densitometrically quantified and the results were expressed as the ratio of P-ERK to ERK, P-JNK to JNK and P-P38 to P38. The data are presented as the means $\pm \mathrm{SD} .{ }^{* * *} \mathrm{P}<0.001,{ }^{* *} \mathrm{P}<0.01$. All data were obtained from at least three independent experiments.

proliferation of NP cells at different concentration, and there is a statistically significant difference between different treatment in early and late apoptosis, but the apoptosis rate could be ignored as the apoptosis rate is too little in different treatment. As the total apoptosis rate has no difference between LPS and LPS with CY group, there is no cytotoxicity of CY to NP cells. Furthermore, our research showed that CY produced pharmacological anti-inflammatory reaction and anti-degeneration results in LPS-induced NP cells for the first time. And our study also evidenced that CY could block the LPS-induced activation of the MAPK pathway in NP cells.

The gene expression of ADAMTSs and MMPs has been a wide range of researches in the stage of IVD degeneration (27). According to many researches, MMP-3 are not expressed in normal human intervertebral discs but have up-regulated expression in degenerated human intervertebral discs. Besides, the protein expression of MMP-3 has a positive correlation with IVD histomorphological degenerative studies (28). The upregulated expression of ADAMTSs has also been detected in degenerative intervertebral discs. ADAMTS-4 and ADAMTS-5 have been revealed as the most important aggrecanases because of their strong abilties in cleaving aggrecan among the 20 various ADAMTSs (29). Inhibitors of ADAMTSs and MMPs have a therapeutic action on IDD in vitro and in vivo studies (30). Aggrecan and collagen II are the main elements of nucleus pulposus, and the decrease of collagen II content is highly correlated with IVD degeneration (31). Our research shows that CY can both prevent LPS-induced collagen II and aggrecan loss and induce their synthesis.

We also demonstrated that CY could inhibit LPS-induced inflammation of NP cells. Previous studies suggested that LPS markedly induced gene upregulation and the production of various proinflammatory cytokines in NP cells (32). TNF- $\alpha$ secreted from inflammatory cells and IVD cells triggers MMPs expression which ends up in vicious cycle of cell apoptosis and matrix degradation (33). The result of the current study demonstrated CY can down-regulate TNF- $\alpha$ expression. TNF- $\alpha$ blocker is now widely used in the treatment of inflammatory arthritis and in certain cases of IVD herniation (34). The MAPK pathways play important roles in the regulation of the inflammatory response (35). The effect of inhibiting p38 expression in NP cells was tested in previous study, the result indicated that inflammatory cytokines induced caveolin- $1 / \beta$-catenin signalling in rat nucleus pulposus cell apoptosis through the p38 MAPK pathway (36). The role of the ERK pathway had also been investigated in human intervertebral disc, and exogenous and autocrine growth factors could stimulate human intervertebral disc cell proliferation via the ERK and Akt pathways (37). And another research showed that crocin exerts anti-inflammatory and anti-catabolic effects on rat intervertebral discs by suppressing the activation of JNK. And JNK is a critical MAPK pathway for intervertebral disc degeneration (15). Though MAPK pathway is related to NP cell death, CCK8 and apoptosis assay showed that there was no impact on NP cell proliferation and total apoptosis following CY treatment. That revealed that there may be other signaling influencing NP cell death. And in our study, MAPK pathway was activated after inflammatory stimulation, so MAPK pathway is more related to inflammatory. Our western blotting results showed that CY inhibited the activation of MAPK pathway in NP cells, thus exerting anti-inflammation effect. So the inhibitory effect of CY on LPS induced inflammation of NP cells was through suppressing MAPK pathway.

As the above, we are honored to report the role of $\mathrm{CY}$ in LPS-induced inflammatory and matrix degradation in the intervertebral disc. We found that $\mathrm{CY}$ could indirectly or directly affect the vitality of MAPK signaling and PG content of intervertebral discs. However, more investigations should conducted following this basal research. Firstly, the in-depth molecular mechanisms controlling the CY-mediated transformations to inflammatory- and PG-related signaling pathways should be better stated. Secondly, animal experients should be constructed to verify the therapeutic effect of $\mathrm{CY}$ in vivo. Finally, our results should be verified by patient treatment.

Taken together, our study reveals that CY could exhibit a strong anti-inflammatory and anti-degeneration effect by suppressing LPS-induced MAPK activation in NP cells. CY may be a potential new traditional Chinese medicine for curing IDD in the future. However, more and further studies are required to confirm this. 


\section{Acknowledgements}

This study was supported by grants from Research project of Shanghai municipal health and Family Planning Commission (grant no. 201640304).

\section{References}

1. Li Y, Li K, Mao L, Han X, Zhang K, Zhao C and Zhao J: Cordycepin inhibits LPS-induced inflammatory and matrix degradation in the intervertebral disc. PeerJ 4: e1992, 2016.

2. Li Y, Li K, Han X, Mao C, Zhang K, Zhao T and Zhao J: The imbalance between TIMP3 and matrix-degrading enzymes plays an important role in intervertebral disc degeneration. Biochem Biophys Res Commun 469: 507-514, 2016.

3. Campbell RJ, Mobbs RJ and Phan K: Evidence update-association between CILP and degeneration of the intervertebral disc: A meta-analysis. J Spine Surg 2: 242-243, 2016.

4. Ye S, Ju B, Wang H and Lee KB: Bone morphogenetic protein-2 provokes interleukin-18-induced human intervertebral disc degeneration. Bone Joint Res 5: 412-418, 2016.

5. Feng Y, Egan B and Wang J: Genetic factors in intervertebral disc degeneration. Genes Dis 3: 178-185, 2016.

6. Teichtahl AJ, Urquhart DM, Wang Y, Wluka AE, O'Sullivan R, Jones $\mathrm{G}$ and Cicuttini FM: Lumbar disc degeneration is associated with modic change and high paraspinal fat content-a 3.0T magnetic resonance imaging study. BMC Musculoskelet Disord 17: 439, 2016.

7. Hart LG, Deyo RA and Cherkin DC: Physician office visits for low back pain. Frequency, clinical evaluation, and treatment patterns from a U.S. national survey. Spine (Phila Pa 1976) 20 $11-19,1995$.

8. Liu MC, Chen WH, Wu LC, Hsu WC, Lo WC, Yeh SD, Wang MF, Zeng R and Deng WP: Establishment of a promising human nucleus pulposus cell line for intervertebral disc tissue engineering. Tissue Eng Part C Methods 20: 1-10, 2014.

9. Kim JS, Ellman MB, Yan D, An HS, Kc R, Li X, Chen D, Xiao G, Cs-Szabo G, Hoskin DW, et al: Lactoferricin mediates anti-inflammatory and anti-catabolic effects via inhibition of IL-1 and LPS activity in the intervertebral disc. J Cell Physiol 228: 1884-1896, 2013

10. Wang B, Wang D, Yan T and Yuan H: MiR-138-5p promotes TNF- $\alpha$-induced apoptosis in human intervertebral disc degeneration by targeting SIRT1 through PTEN/PI3K/Akt signaling. Exp Cell Res 345: 199-205, 2016.

11. Liu XG, Hou HW and Liu YL: Expression levels of IL-17 and TNF- $\alpha$ in degenerated lumbar intervertebral discs and their correlation. Exp Ther Med 11: 2333-2340, 2016.

12. Yang W, Yu XH, Wang C, He WS, Zhang SJ, Yan YG, Zhang J, Xiang YX and Wang WJ: Interleukin-1 $\beta$ in intervertebral disk degeneration. Clin Chim Acta 450: 262-272, 2015.

13. Hu B, Shi C, Xu C, Cao P, Tian Y, Zhang Y, Deng L, Chen H and Yuan W: Heme oxygenase-1 attenuates IL-1 $\beta$ induced alteration of anabolic and catabolic activities in intervertebral disc degeneration. Sci Rep 6: 21190, 2016.

14. Fang $\mathrm{F}$ and Jiang D: IL-1 $\beta /$ HMGB1 signalling promotes the inflammatory cytokines release via TLR signalling in human intervertebral disc cells. Biosci Rep 36: pii: e00379, 2016.

15. Li K, Li Y, Ma Z and Zhao J: Crocin exerts anti-inflammatory and anti-catabolic effects on rat intervertebral discs by suppressing the activation of JNK. Int J Mol Med 36: 1291-1299, 2015.

16. Zhang Y, Liu L, Wang S, Zhao Y, Liu Y, Li J, Nie L and Cheng L: Production of CCL20 on nucleus pulposus cells recruits IL-17-producing cells to degenerated IVD tissues in rat models J Mol Histol 47: 81-89, 2016.

17. Karli P, Martlé V, Bossens K, Summerfield A, Doherr MG, Turner P, Vandevelde M, Forterre F and Henke D: Dominance of chemokine ligand 2 and matrix metalloproteinase- 2 and -9 and suppression of pro-inflammatory cytokines in the epidural compartment after intervertebral disc extrusion in a canine model. Spine J 14: 2976-2984, 2014.

18. Cheng CY and Lee YC: Anti-inflammatory effects of traditional Chinese medicines against ischemic injury in in vivo models of cerebral ischemia. Evid Based Complement Alternat Med 2016: 5739434, 2016.
19. Zhu F, Yin L, Ji L, Yang F, Zhang G, Shi L and Xu L: Suppressive effect of Sanmiao formula on experimental gouty arthritis by inhibiting cartilage matrix degradation: An in vivo and in vitro study. Int Immunopharmacol 30: 36-42, 2016.

20. Wang CC, Choy CS, Liu YH, Cheah KP, Li JS, Wang JT, Yu WY, Lin CW, Cheng HW and Hu CM: Protective effect of dried safflower petal aqueous extract and its main constituent, carthamus yellow, against lipopolysaccharide-induced inflammation in RAW264.7 macrophages. J Sci Food Agric 91: 218-225, 2011.

21. Kohno Y, Totsuka K, Ikoma S, Yoda K, Shibata M, Matsushima R, Tomita Y, Maeda Y and Kobayashi K: Photostability enhancement of anionic natural dye by intercalation into hydrotalcite. J Colloid Interface Sci 337: 117-121, 2009.

22. Fan S, Lin N, Shan G, Zuo P and Cui L: Safflower yellow for acute ischemic stroke: A systematic review of randomized controlled trials. Complement Ther Med 22: 354-361, 2014.

23. Zhou MX, Fu JH, Zhang Q and Wang JQ: Effect of hydroxy safflower yellow A on myocardial apoptosis after acute myocardial infarction in rats. Genet Mol Res 14: 3133-3141, 2015.

24. Han XG, Li Y, Mo HM, Li K, Lin D, Zhao CQ, Zhao J and Tang TT: TIMP3 regulates osteosarcoma cell migration, invasion, and chemotherapeutic resistances. Tumour Biol 37: 8857-8867, 2016.

25. Han XG, Du L, Qiao H, Tu B, Wang YG, Qin A, Dai KR, Fan QM and Tang TT: CXCR1 knockdown improves the sensitivity of osteosarcoma to cisplatin. Cancer Lett 369: 405-415, 2015.

26. Li HX, Han SY, Wang XW, Ma X, Zhang K, Wang L, Ma ZZ and Tu PF: Effect of the carthamins yellow from Carthamus tinctorius L. on hemorheological disorders of blood stasis in rats. Food Chem Toxicol 47: 1797-1802, 2009.

27. Vo NV, Hartman RA, Yurube T, Jacobs LJ, Sowa GA and Kang JD: Expression and regulation of metalloproteinases and their inhibitors in intervertebral disc aging and degeneration. Spine J 13: 331-341, 2013.

28. Weiler C, Nerlich AG, Zipperer J, Bachmeier BE and Boos N: 2002 SSE award competition in basic science: Expression of major matrix metalloproteinases is associated with intervertebral disc degradation and resorption. Eur Spine J 11: 308-320, 2002.

29. Gendron C, Kashiwagi M, Lim NH, Enghild JJ, Thøgersen IB, Hughes C, Caterson B and Nagase H: Proteolytic activities of human ADAMTS-5: Comparative studies with ADAMTS-4. J Biol Chem 282: 18294-18306, 2007.

30. Leckie SK, Bechara BP, Hartman RA, Sowa GA, Woods BI, Coelho JP, Witt WT, Dong QD, Bowman BW, Bell KM, et al: Injection of AAV2-BMP2 and AAV2-TIMP1 into the nucleus pulposus slows the course of intervertebral disc degeneration in an in vivo rabbit model. Spine J 12: 7-20, 2012.

31. Li Y, Li K, Hu Y, Xu B and Zhao J: Piperine mediates LPS induced inflammatory and catabolic effects in rat intervertebral disc. Int J Clin Exp Pathol 8: 6203-6213, 2015.

32. Iwata M, Ochi H, Asou Y, Haro H, Aikawa T, Harada Y, Nezu Y, Yogo T, Tagawa M and Hara Y: Variations in gene and protein expression in canine chondrodystrophic nucleus pulposus cells following long-term three-dimensional culture. PloS One 8: e63120, 2013

33. Kang YM, Hong SH, Yang JH, Oh JC, Park JO, Lee BH, Lee SY, Kim HS, Lee HM and Moon SH: Pamidronate down-regulates tumor necrosis factor-alpha induced matrix metalloproteinases expression in human intervertebral disc cells. J Bone Metab 23: $165-173,2016$.

34. Williams LM, Lali F, Willetts K, Balague C, Godessart N, Brennan F, Feldmann $M$ and Foxwell BM: Rac mediates TNF-induced cytokine production via modulation of NF-kappaB. Mol Immunol 45: 2446-2454, 2008.

35. Goldring MB, Otero M, Plumb DA, Dragomir C, Favero M, El Hachem K, Hashimoto K, Roach HI, Olivotto E, Borzì RM and Marcu KB: Roles of inflammatory and anabolic cytokines in cartilage metabolism: Signals and multiple effectors converge upon MMP-13 regulation in osteoarthritis. Eur Cell Mater 21: 202-220, 2011

36. Wang J, Chen H, Cao P, Wu X, Zang F, Shi L, Liang L and Yuan W: Inflammatory cytokines induce caveolin- $1 / \beta$-catenin signalling in rat nucleus pulposus cell apoptosis through the p38 MAPK pathway. Cell Prolif 49: 362-372, 2016.

37. Pratsinis H, Constantinou V, Pavlakis K, Sapkas G and Kletsas D: Exogenous and autocrine growth factors stimulate human intervertebral disc cell proliferation via the ERK and Akt pathways. J Orthop Res 30: 958-964, 2012. 